\title{
A USABILIDADE DE UM AMBIENTE VIRTUAL DE APRENDIZAGEM: UM ESTUDO SOBRE O MOODLE NO IFRN - CAMPUS CURRAIS NOVOS
}

\author{
G. S. SANTOS, L. A. BALBINO e D. C. GOMES* \\ Instituto Federal de Educação, Ciência e Tecnologia do Rio Grande do Norte - Campus Currais Novos \\ danilo.cortez@ifrn.edu.br*
}

Artigo submetido em abril/2015 e aceito em outubro/2015

DOI: 10.15628/holos.2015.2957

\section{RESUMO}

O Moodle, ambiente virtual de aprendizagem derivado do conceito de e-Learning, foi implantado em diversas instituições de ensino, aumentando assim a oferta de cursos de ensino a distância consideravelmente na última década, bem como as instituições que atuam com essa metodologia. Destaca-se na modalidade de educação a distância, a importância da estrutura fornecida pela instituição aos alunos que deve permear por características baseadas numa usabilidade adequada, pois é através da interface que o usuário/aluno percebe, vê e busca as informações. Nessa perspectiva, o presente estudo buscou identificar as características referentes à usabilidade do moodle no IFRN - Campus Currais Novos. A pesquisa, feita no período de dezembro de 2014 a janeiro de 2015, de caráter descritivo e de campo foi realizada com 153 alunos (com 86 respostas válidas) do curso técnico em Segurança do Trabalho através da aplicação de questionário em que os dados foram coletados e em seguida analisados. Os resultados revelaram que a maior parte dos alunos pesquisados está satisfeita com o moodle, porém, uma parcela considerável dos alunos se mostraram descontentes com o mesmo, explicitando, em sua maioria, que o design precisa ser melhorado. Por fim, os resultados apresentados se limitam a uma realidade específica de um ambiente virtual, de um curso e uma instituição, não podendo ser generalizado para outras instituições, cursos ou ambientes virtuais.

PALAVRAS-CHAVE: Usabilidade. E-Learning. Ambiente Virtual de Aprendizagem. Moodle.

\section{THE USABILITY OF THE VIRTUAL LEARNING ENVIRONMENT: A STUDY ON THE IFRN'S MOODLE - CAMPUS CURRAIS NOVOS}

\begin{abstract}
The Moodle, virtual learning environment derivative of the concept of e-Learning, has been implemented in various educational institutions, thus increasing the supply of distance learning courses in the last decade, and the institutions that work with this methodology. Stands out in the distance education modality, the importance of the framework provided by the institution for the students should permeate features based on an appropriate usability as it is through the interface that the user/student perceives, sees and search the information. From this perspective, this study sought to identify the characteristics for usability moodle in IFRN - Campus Currais Novos. The survey, conducted from December
\end{abstract}

2014 to January 2015, a descriptive and field research was carried out with 153 Occupational Safety students (with 86 valid responses) through a questionnaire in which data were collected and then analyzed. The results revealed that most of the students surveyed are satisfied with Moodle, however, a considerable number of students were dissatisfied with it, explaining, in most cases, the design needs to be improved. Finally, the results are limited to a specific reality of a virtual environment, a course and an institution, can not be generalized to other institutions, courses or virtual environments.

KEYWORDS: Usability. E-Learning. Virtual Learning Environment. Moodle. 


\section{INTRODUÇÃO}

Uma das maiores contribuições tecnológicas na educação surgiu por volta dos anos 1990, a qual procurava integrar os recursos disponíveis pela internet no processo de aprendizado. A mesma ficou conhecida como e-Learning.

Com o tempo, apesar de demorado, o e-Learning se tornou cada vez mais necessário, pois o mesmo foi se desenvolvendo para resolver o problema do pouco tempo diário. Já que as pessoas não tinham tempo para ir até o conhecimento, o conhecimento iria até elas se adequando ao horário que as mesmas achassem mais adequado. Além desse benefício significativo, o e-Learning ainda proporcionava várias outras vantagens aos seus usuários. Mas apesar de todos os benefícios, esse sistema foi rejeitado por um bom tempo pois o mesmo apresentava algumas deficiências significativas.

Tais deficiências eram causadas por problemas de usabilidade no sistema que é basicamente problemas em questões de interações homem-máquina. Deficiências desse gênero afetam muito o desempenho do sistema, e apesar de já se encontrarem vários arquivos e normas padronizadas sobre como melhorar a usabilidade do sistema, o mesmo não parece ser tão valorizado quanto deveria.

Nesse trabalho deu-se ênfase aos estudos de usabilidade levando em consideração uma das muitas variantes do e-Learning que é categorizada como AVA ou Ambientes Virtuais de Aprendizagem, que são amplamente utilizados por escolas, institutos, universidades e empresas diversas, dinamizando assim sua forma de ensino e/ou treinamento.

Referindo-se ao uso em instituições de ensino, mais especificamente os institutos federais, pode-se afirmar que no Instituto Federal de Educação, Ciência e Tecnologia do Rio Grande do Norte - Campus Currais Novos, esse tipo de tecnologia já está sendo utilizado, o que implica por parte da instituição uma busca constante por atualização e melhores condições desse ambiente virtual. Nesse sentido, vale ressaltar que no processo de implementação e manutenção do e-Learning, algumas dificuldades podem aparecer, especialmente quanto à usabilidade dos ambientes virtuais de aprendizagem.

Desse modo, surge o seguinte problema que norteou este trabalho: Quais as características referentes à usabilidade do ambiente virtual de aprendizagem do IFRN - Campus Currais Novos?

A fim de que pudéssemos chegar a uma conclusão para tal questionamento, essa pesquisa propôs analisar o grau de satisfação do usuário do sistema Moodle; suas ferramentas, características e funcionalidades através de questionários; e propor melhoramentos a partir dos resultados obtidos com as análises.

Este trabalho é relevante para aqueles que atuam na educação à distância, bem como para todos os envolvidos com a tecnologia da informação, pois pode ajudar com sugestões de melhoria a partir de um diagnóstico de determinada realidade.

Em relação às necessidades de mudança e melhorias nesses sistemas de aprendizagem virtuais, os profissionais da área de informática acabam sendo protagonistas nesse processo, especialmente os desenvolvedores web, de forma mais específica, quando se trata da usabilidade, que é a chave para a interação aluno-plataforma de ensino e que deveria estar entre os requisitos principais no desenvolvimento deste ambiente virtual, uma vez que o Moodle é uma plataforma 
que auxilia a educação à distância e o mesmo pode influenciar na qualidade desta modalidade de ensino.

Sendo assim, percebeu-se como fator preponderante, a análise do Moodle de acordo com a percepção dos usuários (alunos) no que se refere à usabilidade da plataforma para que houvesse um diagnóstico mais preciso sobre as possíveis dificuldades encontradas pelos alunos.

Por último, esta pesquisa corrobora com a realidade da educação à distância, a qual está sendo cada vez mais requisitada no Brasil e no mundo, tendo assim a necessidade que a qualidade de ensino também cresça para suprir tal demanda.

\section{REVISÃO BIBLIOGRÁFICA}

\subsection{E-learning - Conceitos e Características}

O e-Learning, por seu termo ser de uso recente (LEVY, 2003), possui o significado ainda um pouco abstrato variando de autor e obra. Segundo Lima; Capitão (2003), o e-Learning é caracterizado por uma aprendizagem realizada através da rede, meio por onde será distribuído o conteúdo, que deve ser apresentado de forma interativa e em formato multimídia; também é por onde ocorre a interação social e o apoio na aprendizagem.

Outra definição que é bastante utilizada é a perspectiva do termo e-Learning como "ensino a distância via internet", já que uma das características do e-Learning é que o mesmo está essencialmente associado à Internet e ao serviço WWW. De acordo com Gomes (2005), através da sua facilidade de acesso, diversidade de ferramentas e os serviços de comunicação, o usuário pode buscar a informação desejada, independente de tempo e lugar onde esteja.

Resumidamente, a Cisco Systems (2001) sugere que o e-Learning é simplesmente "a aprendizagem baseada na internet". No decorrer do trabalho, esse foi o conceito adotado.

\subsection{Histórico do E-learning}

De acordo com Rosenberg (2002), a origem do mesmo vem dos CBTs (computed-based training ou treinamento baseado no computador) que nas décadas de 70 e 80 tiveram um grande foco de empresas devido à chegada do computador pessoal ao mercado, pois este possibilitaria uma base incorporada de hardware para executar seus programas.

No entanto, esse foco foi diminuindo já que devido às diferenças de hardware, software, linguagens de programação, entre outros problemas, mal um programa chegava ao mercado, mudanças rápidas nas plataformas de tecnologia o tornavam obsoleto (ROSENBERG, 2002).

Porém, a partir da década de 90 , esse quadro veio a mudar drasticamente e, com o avanço das tecnologias de informação e comunicação, o problema do e-Learning passou a não ser mais diferença de hardware, software, linguagens de programação, pois "a preocupação com as diferenças nas plataformas e sistemas operacionais está rapidamente desaparecendo" uma vez que o e-Learning "aproveita os protocolos e navegadores universais da Internet" (ROSENBERG, 2002, p. 28).

Em conjunto com esse fator também houveram mudanças no estilo de vida da sociedade, já que atualmente o profissional necessita estar constantemente atualizando suas informações, 
aumentando assim, o período de aprendizado para toda uma vida, ao invés de apenas alguns anos como era praticado anteriormente. Com isso, houve uma necessidade de uma forma de ensino que se adequasse a suas necessidades, uma vez que os estudantes também eram profissionais de alguma área e não tinham uma disponibilidade de tempo de um jovem que não atua no mercado de trabalho.

Os cursos de e-Learning, portanto, se tornaram indispensáveis no mundo, mas no Brasil, ele não apresentou o mesmo ritmo de aceitação que nos Estados Unidos e Europa, pois essa tecnologia chegou mais tarde aqui e já foi apresentando muitas inovações. Além do mais, havia muitos produtos no mercado, mas nem todos tinham sido devidamente testados, o que acabou por criar um receio no uso desses sistemas (FRANCIS, 2002).

Todavia, o Brasil soube se adaptar razoavelmente bem a esse novo modelo e o e-learning, em 1998, já começou a fazer parte da legislação brasileira como uma modalidade da EaD (PEREIRA et al., 2007).

Segundo dados do Ibope (2010), no ano de 2010, houve um grande crescimento no número de usuários da internet chegando a atingir a marca de 67,5 milhões de pessoas no Brasil. Consequentemente, também houve um crescimento no número de cursos da EaD e nesse mesmo ano, de acordo com Soeltl, presidente do portal e-Learning Brasil, já haviam 338 organizações que utilizavam o e-Learning, com a grande maioria situada na região Sudeste.

Atualmente, os órgãos de ensino mais preocupados em implantar algum tipo de Educação à Distância (EaD) do tipo e-Learning no Brasil são os Institutos de Ensino Superior (FREITAS, 2009). Os mesmos utilizam interfaces de Ambientes Virtuais de Aprendizagem e em 2006, já haviam 889 cursos a distância na área da educação (FREITAS, 2009).

\subsection{Ambientes Virtuais de Aprendizagem}

Os Ambientes Virtuais de Aprendizado (AVA) já anteriormente citados consistem em um conjunto de ferramentas eletrônicas voltadas ao processo ensino-aprendizagem. (MCKIMM; JOLLIE; CANTILLON, 2003).

Segundo Almeida (2006), as ferramentas mais comuns utilizadas por AVA's são: login do usuário; perfil do usuário; mural; agenda; conteúdo; avaliação; chat; fórum; matrícula; anotações; turma.

Entre os autores pode-se diferenciar a nomenclatura das ferramentas, porém suas utilidades são basicamente as mesmas. Entretanto, quanto ao conceito, alguns podem ver o AVA como um mediador do processo ensino-aprendizagem a distância (PEREIRA et al., 2007). E também há quem o descreva como um software baseado em um servidor e organizado a fim de gerenciar e administrar os vários aspectos do ensino-aprendizagem (MILLIGAN, 1999).

Como foi visto no caso do e-Learning, a definição de AVA também se encontra em um estágio de formação, portanto, a definição de AVA que mais se adequou aos estudos do presente trabalho foi de que o mesmo é um software modelado para mediar o processo ensinoaprendizagem.

Como exemplos de AVA's utilizados no Brasil, pode-se citar: 
a) Moodle: O Moodle é uma plataforma de aprendizagem designada para prover aos educadores, administradores e estudantes, um sistema robusto, seguro e integrado a fim de que possa ser criado ambientes de aprendizado personalizados.

b) Solar: O SOLAR é um ambiente virtual de aprendizagem desenvolvido pelo Instituto UFC Virtual, da Universidade Federal do Ceará. Ele é orientado ao professor e ao aluno, possibilitando a publicação de cursos e a interação com os mesmos.

c) TelEduc: O TelEduc é um ambiente de e-Learning para a criação, participação e administração de cursos na Web.

Como objeto de estudo desse trabalho, mais ênfase foi dada à plataforma Moodle em detrimento das outras anteriormente citadas.

\subsection{Moodle}

A palavra Moodle é um acrônimo para Modular Object-Oriented Dynamic Learning Environment, mas também é um verbo que descreve o processo de passar por algo despreocupadamente fazendo as coisas quando sentir vontade de fazê-las tornando, assim, as tarefas mais agradáveis, o que acaba por estimular a introspecção e a criatividade.

A fim de alcançar esse objetivo proposto pelo seu nome, ele possui software livre, de código aberto e sua estrutura básica é organizada através de cursos, o que possibilita aos educadores a criação de seu próprio website privado adicionando os cursos de sua preferência que estende o aprendizado a qualquer hora e qualquer lugar.

Estes são basicamente páginas ou áreas dentro do Moodle, no qual, professores podem apresentar seus recursos de aprendizagem e atividades para os estudantes. Podem existir diferentes layouts, porém, normalmente incluem um número de seções centrais onde materiais são exibidos e ao lado são oferecidos recursos extras ou informações adicionais.

Os cursos são organizados em categorias, por exemplo: Os cursos de Física, Química e Biologia normalmente podem estar na categoria de Ciência.

Além dessa estrutura de cursos, o Moodle também possui 20 diferentes tipos de atividades válidas (fóruns, glossários, wikis, tarefas, quizzes, enquetes, jogos, lista de melhores jogadores, banco de dados, etc.) e cada uma dessas pode ser customizada.

Em conjunto com essas atividades também há várias ferramentas como blogs, chats, listas de participantes, classificações, relatórios, integração com outros sistemas entre outros.

Apesar de todas essas ferramentas e facilidades para disponibilizar a maior dinamicidade possível em seu sistema, o fato de ser altamente personalizável o torna sujeito a falhas na fase de personalização, principalmente, falhas envolvendo problemas de usabilidade.

\subsection{Usabilidade}

Segundo a NBR 9126 da ISO (2004), usabilidade é a "a capacidade do produto de software ser compreendido, seu funcionamento aprendido, ser operado e ser atraente ao usuário.", onde suas sub características são: inteligibilidade, apreensibilidade, operacionalidade e atratividade. 
Assim, no contexto da web, a usabilidade estudaria a interface do programa especificado, já que é através dela que ocorre a interação do usuário com o sistema, onde seria definido o objetivo a ser alcançado.

Souza (2004), afirma que a usabilidade visa, principalmente, minimizar o tempo de aprendizagem; a irritação dos usuários na execução das tarefas; a subutilização dos recursos disponíveis; os erros do usuário e o baixo rendimento do trabalho. Sendo esses objetivos alcançados pelas seguintes metas: a) eficiência: cumprir os objetivos para o qual foi criada; b) segurança: permitir o manuseio de forma segura para o usuário e para o próprio sistema; c) utilidade: ser útil para o usuário e para os problemas que ele deseja desempenhar; d) aprendizagem: ser uma interface de fácil aprendizado para o usuário; e) memorização: ser fácil de lembrar como usá-lo (SILVA et al., 2014). Com isso, nota-se que a usabilidade está diretamente relacionada à interação homem-máquina, portanto os mais prejudicados devido a problemas na interface seriam os usuários finais, e no caso dos AVA's, essa deficiência chegaria a afetar o desempenho acadêmico do aluno.

Devido a tal importância que a usabilidade possui no processo de desenvolvimento de softwares, foram formuladas algumas recomendações padrão a serem seguidas na hora da criação da interface gráfica e já existem várias técnicas eficientes de avaliação da usabilidade, além de vários tipos de instrumentos avaliativos, as quais podem ser aplicadas tanto em sites educacionais, quanto em qualquer outro site.

Entre as técnicas de avaliação da usabilidade, Nielsen e Landauer (1993) explicitam que a heurística é uma das mais práticas e econômicas, pois permite identificar problemas logo na fase de desenvolvimento, porém, nem todos os problemas são detectáveis através da avaliação heurística, então são realizados os testes com utilizadores, estes "permitem validar os testes de heurística e corrigir outros erros que não foram detectados” (ALVES e PIRES, 2002, p. 3).

Outra técnica de grande importância na avaliação da usabilidade são as de princípio ergonômico, as quais "ajudam os projetistas a obter sistemas e componentes que podem ser usados de maneira eficaz, eficiente, segura e confortável." (MEDEIROS e CYBIS, 2000, p. 1).

Ainda segundo Medeiros e Cybis (2000), o que os diferencia dos princípios heurísticos, é que eles permitem a classificação de satisfação dos indicadores obtidos, determina metas para os graus de satisfação globais e de cada princípio, atua pontualmente, e possui uma abordagem metódica.

As técnicas heurísticas, ergonômicas e os testes com utilizadores são apenas algumas das formas de avaliação de usabilidade em um software ou website. 0 mesmo também pode ser avaliado através de instrumentos avaliativos, como diretrizes, checklists, escalas de avaliação, formulários, questionários, sistemas e ferramentas híbridas.

Apesar de a usabilidade ser um fator prioritário na indústria de software, uma vez que a competição se dá, em sua maior parte, pela interface do produto, ainda não foi identificado um método que se destacasse como melhor e segundo Senach (1993), cada situação coloca questões originais ao avaliador e, por isso exige a aplicação de métodos e técnicas que melhor se adaptem ao contexto da análise. 
Levando essa ideia em consideração, foram analisados os métodos existentes e identificado o instrumento avaliativo de questionários como melhor forma de avaliação para este caso específico.

\section{METODOLOGIA}

A pesquisa se classifica como descritiva, já que esta "engloba dois tipos: a 'pesquisa documental' e/ou 'bibliográfica' e 'a pesquisa de campo'" (AIDIL e NEIDE, 2007, p. 84), e empregouse a abordagem quantitativa a qual se caracteriza pela utilização de técnicas estatísticas, como percentual, média, entre outras, com variáveis bem definidas a fim de garantir a exatidão dos resultados.

O trabalho também utilizou uma abordagem qualitativa para analisar as respostas das perguntas abertas e subjetivas feitas por meio de um questionário.

O questionário utilizado foi confeccionado exclusivamente para esse estudo possuindo adaptação de outros dois questionários (Questionário de Silva et al. (2014) e o checklist de qualidade da norma ISO 14.598). Também houve uma divisão das questões em tópicos específicos dependendo da natureza da pergunta, com o objetivo de facilitar a compreensão dos entrevistados ao respondê-lo.

A pesquisa se caracterizou como censitária, uma vez que propôs a aplicação do questionário a todos os alunos de três turmas de Segurança do Trabalho (2013.1, 2013.2 e 2014.1) em EaD oferecidos no campus Currais Novos. A aplicação do mesmo ocorreu via web nos dias 2 a 10 de dezembro de 2014, no qual houve pouquíssimas respostas, e 19 a 27 de janeiro de 2015, período em que foi atingido um número significativo de respostas. Foram entrevistadas 153 pessoas, havendo respostas efetivas de um total de 86 pessoas e todas elas possuíam acesso ao sistema Moodle do Instituto Federal de Educação, Ciência e Tecnologia do Rio Grande do Norte através dos cursos em EaD.

Após a aplicação do questionário, as respostas obtidas foram mantidas em um banco de dados online e passadas pelos passos de classificação e tabulação, nos quais consistem respectivamente, na divisão dos dados em partes, colocando-os em ordem, sendo uma maneira de selecionar os dados obtidos e distribuí-los em classes (que representam cada pergunta); e a apresentação dos mesmos em tabelas, para facilitar o processo de análise dos dados (Aidil e Neide, 2007).

Ao serem concluídos esses passos, as informações obtidas passaram inicialmente por um refinamento a fim de identificar possíveis falhas ou erros. Em seguida, as respostas já se encontravam aptas para análise e interpretação, passaram pelos processos de contagem e comparação.

No processo de contagem, primeiro foi analisado o resultado geral da pesquisa para ter uma ideia dos padrões de resposta e depois que foram somadas todas as respostas foi calculada a porcentagem de cada uma para cada questão.

No processo de comparação, foi usada a técnica de tabulação cruzada que consistiu em identificar as variáveis independentes, agrupar as respostas, tabular as respostas das variáveis 
dependentes e gerar a tabela a fim de comparar os valores das duas variáveis e entender como uma afeta a outra para enfim chegar a uma conclusão.

Quanto às respostas subjetivas, foram selecionadas as 5 respostas mais relevantes à pesquisa, de cada questão para serem analisadas mais enfaticamente e contribuírem na conclusão.

\section{RESULTADOS E DISCUSSÕES}

\subsection{Perfil dos entrevistados}

Uma das diversas razões para as pessoas aderirem um curso de EaD é a falta de tempo para se deslocar a uma instituição de ensino. As atividades profissionais estão intimamente envolvidas com esse fato, já que muitas vezes não é possível encontrar um horário vago na rotina de trabalho.

Entre os entrevistados, $61,6 \%$ possuem um emprego e por volta de $38,4 \%$ não possuíam emprego durante o período da coleta, sendo que desses $38,4 \%, 54,5 \%$ possuem idade igual ou inferior a 25 anos.

No Moodle, os próprios alunos são quem administram o tempo dedicado ao estudo e aprendizagem, podendo entrar no ambiente virtual de aprendizagem no horário e local que desejarem.

Conforme pode ser visto no gráfico $1,47,67 \%$ dos entrevistados, ou seja, a maioria, dedicam entre 1 a 2 horas por dia de acesso ao Moodle, enquanto 22,09\% dedicam menos de 1 hora diariamente, sendo que desses $22,09 \%, 57,9 \%$ possuem emprego no momento. Isso implica dizer que um percentual baixo, mas significativo, passa muito pouco tempo no ambiente virtual, o que pode comprometer o processo de ensino-aprendizagem.

\section{Utilização diária do Moodle}

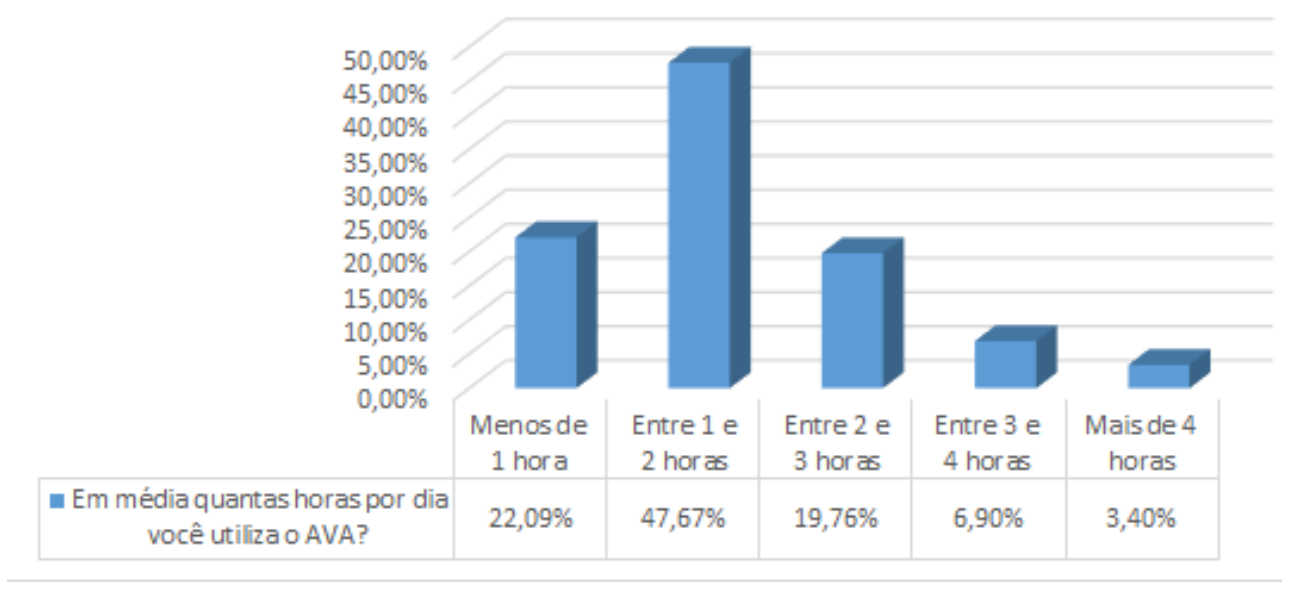

Gráfico 1: Período em horas em que o Moodle é utilizado diariamente

Ainda na questão de utilização diária do Moodle, 19,76\% utilizam-no durante 2 a 3 horas por dia e $64,7 \%$ desses estão em atividade no mercado de trabalho. Entre 3 e 4 horas, o número já começou a reduzir, sendo apenas $6,90 \%$ que passam esse determinado tempo utilizando a plataforma. Por fim, apenas 3,40\% dos entrevistados utilizam o Moodle diariamente por mais de 4 horas, porém, $100 \%$ desses 3,40\% estão empregados e possuem idade entre 31 e 35 anos. 
Os usuários do Moodle podem acessá-lo através de dispositivos móveis, como, por exemplo, o tablet, notebooks, netbooks e laptops, e desktops. Na pesquisa foi constatado que a maioria dos usuários entrevistados utilizam somente dispositivos desktops para realizar o acesso ao Moodle, sendo, em números, um total de $55,81 \%$. A porcentagem de 26,74 foi coletada entre os entrevistados que utilizam ambos desktops e dispositivos móveis para acessar o ambiente virtual de aprendizagem. Apenas 17,44\% utilizam somente dispositivos móveis, porém, esse número relativamente baixo pode ser explicado já que o sistema Moodle esta disponível unicamente para tablet e não para smartphones, este que é um produto que tem sido cada vez mais adquirido nos dias atuais.

A necessidade de uma versão do Moodle para dispositivos móveis além do tablet, notebook, entre outros, foi explicitada por $65,11 \%$ (Sim 41,86; Às vezes 23,25) dos entrevistados, que afirmaram sentir falta de uma versão alternativa para smartphones, entre outros dispositivos móveis. 34,88\% disseram não sentir falta, porém é interessante notar que desse grupo, 76,65\% possuem idade igual ou superior a 26 anos.

Em relação à quantidade de disciplinas cursadas, foi observado que mais de $80 \%$ dos entrevistados cursaram mais de 5 disciplinas no ambiente virtual, sendo que desse total, 64,4\% estão trabalhando no momento. Esse dado mostra que mais da metade conseguiram conciliar o emprego com o curso de $\mathrm{EaD}$. A porcentagem $6,90 \%$ foi coletada entre entrevistados que cursaram 1 disciplina e de 4 a 5 disciplinas, já $1,10 \%$ foi a porcentagem apresentada por pessoas que cursaram de 2 a 3.

\subsection{Avaliação da interface com o usuário, estrutura e funcionalidade do ambiente}

Ao ser estudada a usabilidade na web, o enfoque principal é na interface dos sites, pois é principalmente através desta que ocorre a comunicação com o usuário. A interface de um site deve ser intuitiva o bastante para que o usuário tenha uma boa experiência ao utilizá-lo.

Em relação a intuitividade (identificação dos elementos, recursos e ferramentas presentes), 67,44\% dos usuários entrevistados consideram normal o Moodle, não havendo tanta dificuldade, entretanto, eles afirmam que também não há tanta facilidade. Nenhum dado foi coletado informando que a interface é intuitiva demasiadamente, porém $16,31 \%$ disseram que o formato da interface é pouco ou pouquíssimo intuitivo, mostrando ser um número maior do que as pessoas que acham o formato da interface muito agradável (15,11\%). Esses números são preocupantes para a instituição que busca oferecer um ambiente de aprendizagem adequado para os alunos, pois nesse quesito foram identificadas mais pessoas insatisfeitas com a interface do que satisfeitas.

A organização de um site é imprescindível para que o mesmo facilite a "navegação" do usuário. As informações devem ser claras para que o usuário saiba onde está e para onde deve ir nesse ambiente virtual. A navegabilidade do Moodle, através dos dados coletados, se mostra mais positiva do que negativa, com $20,93 \%$ das pessoas se mostrando muito satisfeitas com a forma de navegação do ambiente e 3,52\% demasiadamente satisfeitas com a navegabilidade.

Ainda nesse aspecto, $58,82 \%$ dos entrevistados se mostraram normalmente satisfeitos e $16,31 \%$ pouco ou pouquíssimos satisfeitos.

Outros dois pontos relevantes para a usabilidade de um site é a disposição de cores e o tamanho e tipo de fontes utilizadas na interface. Quando um site exagera nesses quesitos, este 
tende a ficar sobrecarregado visualmente, prejudicando a visualização das informações. Assim, quanto às cores dispostas na interface do Moodle, 65,11\% dos entrevistados afirmam acharem normal a disposição, $18,60 \%$ estão muito satisfeitos, $12,79 \%$ estão pouco satisfeitos, porém, existem mais pessoas pouquíssimo satisfeitas do que demasiadamente satisfeitas, sendo, respectivamente, $2,32 \%$ e $1,16 \%$.

Já o resultado em relação ao tamanho e tipo de fontes foi um pouco mais positivo, $70,58 \%$ explicitaram que acham normal, $20 \%$ dizem estar muito satisfeitos e 3,48\% demasiadamente. Enquanto 5,83\% estão pouco ou pouquíssimo satisfeitos com o tipo de fontes e seus tamanhos.

Sites pesados são um dos graves problemas que os usuários enfrentam na internet, além de demorarem a abrir, são de difícil navegabilidade e tendem a deixar o computador lento.

A maioria dos entrevistados, 44,18\%, responderam que a utilização dos recursos do computador é normal, não o deixando lento, utilizando somente o necessário. Já $47,66 \%$ das respostas disseram que o Moodle utiliza pouco ou pouquíssimo dos recursos, em contrapartida, $8,13 \%$ disseram que sim, a plataforma utiliza muito ou demasiadamente os recursos do computador, sendo que os $1,16 \%$ das pessoas que responderam "demasiadamente" utilizam somente dispositivos móveis para acessar o ambiente virtual de aprendizagem.

No Moodle, os professores ficam responsáveis por disponibilizarem avisos, datas de tarefas agendadas, entre outras informações. Em relação à visualização dessas informações e do calendário, 37,64\% dos entrevistados dizem estarem pouco ou pouquíssimo satisfeitos, 49,41\% dizem estarem com nível de satisfação normal, já somente $12,93 \%$ estão muito ou demasiadamente satisfeitos.

Uma das pessoas que não está satisfeita enfatiza que a visualização de atividades deveria ter mais destaque na página. Outra diz que o mural de mensagens deveria servir para colocar uma maior quantidade de informações.

No início dos cursos ministrados através do Moodle, existe uma disciplina que ensina aos "recém-chegados" usuários como o ambiente virtual de aprendizagem em questão é utilizado, bem como uma explanação sobre seus recursos, elementos, ferramentas, entre outras informações, todavia, $34,87 \%$ dos entrevistados responderam que essa disciplina facilitou pouco ou pouquíssimo na aprendizagem de como usar o Moodle e $25,88 \%$ responderam que utilizam pouco ou pouquíssimo as informações ensinadas na mesma. Um total de $38,37 \%$ disse que a disciplina facilitou em um nível "normal", enquanto $50 \%$ das respostas coletadas explicitam que utilizam "normal" as informações ministradas nessa ensinadas. Esses dados podem ser um subsídio interessante para a equipe pedagógica (coordenadores, professores e tutores) analisarem a disciplina em questão e proporem melhorias e adaptações que julgarem convenientes em prol do processo de ensino e aprendizagem dos alunos.

Ainda nesse assunto, $24,41 \%$ dos entrevistados disseram que a disciplina de iniciação ao Moodle facilitou muito o uso do mesmo e 2,32\% disseram que facilitou demasiadamente. Já $20 \%$ responderam que usa muito as informações ensinadas na disciplina e 3,52\% que usa demasiadamente.

No Moodle, os usuários usufruem de várias ferramentas para tirar suas dúvidas, tais como fóruns, mensagens, chat. Nesses "locais", as dúvidas dos alunos podem ser respondidas por colegas, tutores e professores, além de facilitar a interação entre eles. Foi verificado que quase 
$60 \%$ dos usuários que responderam o questionário disseram que usam com pouca ou pouquíssima frequência tais ferramentas, enquanto $25,58 \%$ utilizam normalmente o fórum, chat e as mensagens. Um número muito reduzido - 16,27\% - afirmou utilizar com muita ou demasiada frequência essas ferramentas.

É perceptível o elevado índice de alunos que pouco utilizam essas ferramentas, o que pode comprometer o andamento das atividades e demais ações que ocorrem no ambiente virtual de aprendizagem.

Um dos objetivos principais de um ambiente virtual de aprendizagem é gerar resultados positivos nos seus usuários, proporcionando a estes, subsídios e ferramentas que possibilitem um verdadeiro aprendizado ao passo que utilizem o a ambiente. Dessa forma, $36,04 \%$ dos entrevistados disseram que o Moodle gera resultados precisos e dentro do esperado e $20,93 \%$ disseram que são gerados resultados precisos frequentemente, já 37,20\% explicitaram que somente às vezes esses resultados são gerados. No entanto, $5,8 \%$ das pessoas mostraram não estarem satisfeitas com os resultados gerados pelo Moodle, dizendo que o mesmo simplesmente não gera resultados precisos ou raramente o gera.

Primeiramente, para que o Moodle gere resultados positivos nos usuários, este deve propor e disponibilizar realmente aquilo que é apropriado para determinado curso ou disciplina, além de executar essas propostas de forma eficiente e eficaz. Nessa perspectiva, em relação a qualidade das propostas desse ambiente virtual, $74,11 \%$ dos respondentes afirmam positivamente que sim, o moodle desenvolve propostas de forma apropriada e as executando segundo o que foi proposto. Por outro lado, $24,70 \%$ dos entrevistados afirmam que somente às vezes essas propostas são feitas e realizadas de forma coerente. Além do mais, somente 1,17\% afirmam estarem descontentes com o sistema, dizendo que raramente o ambiente virtual de aprendizagem propõe o que realmente deve.

\section{Propostas do ambiente e sua real utilização}

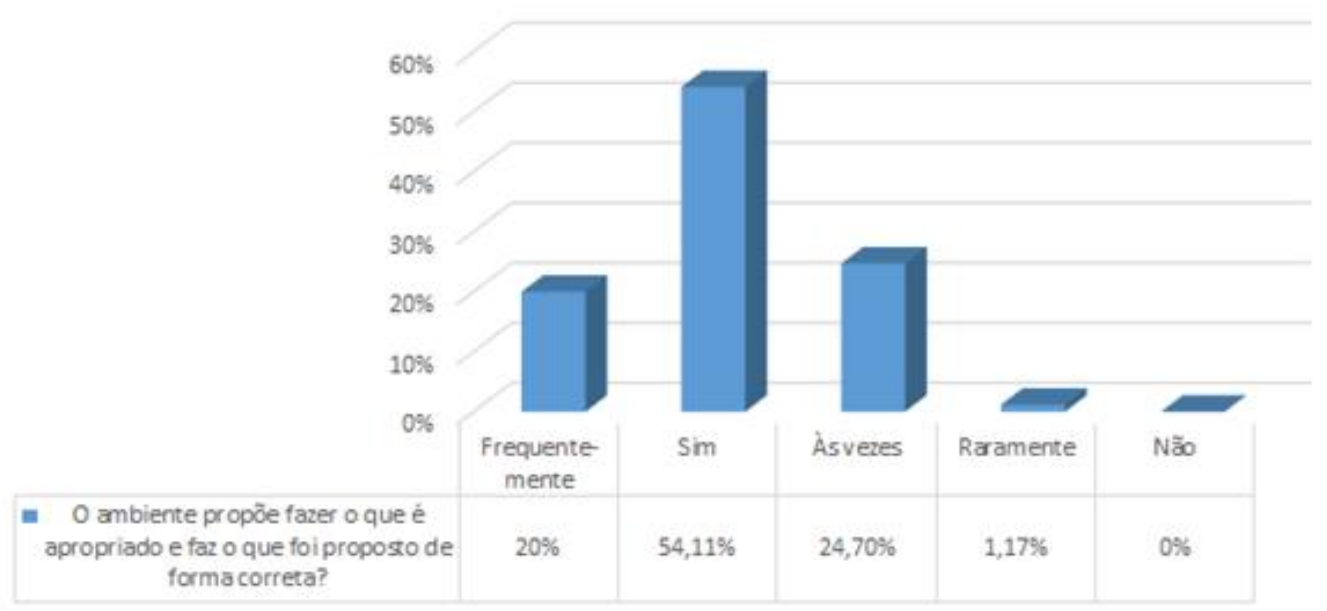

Gráfico 2: Operacionalidade

4.3 O Ambiente Virtual de Aprendizagem como ferramenta mediadora no processo ensino-aprendizagem.

Com a pesquisa pôde-se notar que um dos grandes problemas do EaD é a dificuldade de comunicação entre os alunos e professores, haja vista que os tutores são apenas mediadores dessa 
comunicação. Essa relação importante da EaD foi também observada neste estudo em que os dados mostram que $66,27 \%$ dos entrevistados dizem estar satisfeitos ou totalmente satisfeitos com a forma de interação proporcionada pelo moodle, enquanto um percentual menor, mas não menos importante, de alunos totalmente insatisfeitas, somando $3,48 \%$ e apenas $1,16 \%$ totalmente satisfeitas.

Levando-se em consideração as pessoas que já cursaram mais de 5 disciplinas e certamente tiveram mais contato com o sistema, vê-se uma persistência nos resultados apresentados, pois $94,44 \%$ das pessoas que não se indicaram satisfeitas estão nessa categoria de pessoas que cursaram mais de 5 disciplinas, ou seja, as mesmas já conhecem o moodle a mais tempo e possuem uma opinião bem relevante sobre a temática.

Os dados coletados revelam pontos substanciais no que se refere à interação entre os participantes desse ambiente virtual, pois a falta de interação é mais observada no aspecto de resolução de dúvidas, no qual um percentual ainda menor de pessoas estão satisfeitas, porém, ainda representando a maioria, $62,34 \%$. Por outro lado, os $37,66 \%$ restantes se encontram indecisos em sua maior parte, também havendo entre eles pessoas insatisfeitas e uma pequena porcentagem, 2,35\%, totalmente insatisfeitas. Dentre os $36,66 \%$ que não se disseram satisfeitos, se encontram $62,5 \%$ que também não se satisfizeram com a forma de interação do sistema.

Em contrapartida, dentre as pessoas que afirmam usar muito ou demasiadamente as ferramentas do sistema para sanar dúvidas, $85,71 \%$ delas estão satisfeitas com relação à resolução das dúvidas pelos tutores, ou seja, dentre as pessoas que mais procuram tirar dúvidas, a maioria se encontra satisfeita com o tratamento em relação as mesmas. Destaca-se aqui a diferença das atuações dos tutores e professores, pois estes são os responsáveis pelas disciplinas e pelo processo direto de ensino, enquanto aqueles dão os subsídios necessários para a organização e melhor aproveitamento dos alunos em relação ao ambiente virtual e outras dúvidas referentes ao curso e andamento do mesmo.

Destaca-se ainda, os resultados que apontam o grau de eficiência das ferramentas disponibilizadas no moodle para auxiliar seus usuários. Assim, os dados coletados se mostraram, nesse caso, mais contraditórios, com quase $50 \%$ dos mesmos sendo negativos quanto à eficiência das ferramentas do Moodle, enquanto 39,53\% das pessoas responderam que as ferramentas citadas (chat, fóruns, glossários, recursos, calendário) nem sempre satisfaziam suas necessidades, tendo um percentual de $4,65 \%$ das pessoas afirmando que as mesmas simplesmente não supriam e outras $4,65 \%$, que raramente atendiam as necessidades deles. Por outro lado, $27,90 \%$ indicaram que as ferramentas supriam suas necessidades e $23,25 \%$, que supriam frequentemente.

Em conjunto com tais resultados, a ferramenta que mais contribuiu para o aprendizado dos entrevistados foi a de disponibilização de recursos (materiais didáticos) com uma porcentagem de $58 \%$. Em seguida, foram os fóruns com $22,9 \%$, glossários com $6,87 \%$, chat com $5,34 \%$ e outros (normalmente a ferramenta de mensagens) com 6,87\%.

Segundo os estudantes, os materiais didáticos foram o que mais contribuíram para o aprendizado, pois está disponível a qualquer hora e em qualquer momento (pode ser salvo em memórias externas como pendrives, ou pode ser impresso), além de apresentarem os conteúdos principais a serem estudados nas disciplinas. 
Em relação aos chats, nem todos possuem disponibilidade para participar (estes possuindo horários determinados) ou não possuem tempo suficiente para ficar estudando diretamente pela plataforma através de fóruns ou de glossários.

Os fóruns também foram avaliados de forma positiva, pois, segundo os entrevistados, ajudam muito a sanar as dúvidas tanto através das perguntas anteriormente resolvidas quanto ao tirar suas próprias dúvidas as quais o material disponibilizado não pôde esclarecer. Em contrapartida, houve pessoas que reclamaram da desorganização dos fóruns e chats, os quais não possuíam uma separação de conteúdo; e também houve argumentos contra os materiais didáticos, afirmando que os mesmos eram de difícil compreensão.

\section{Qualidade do aprendizado}

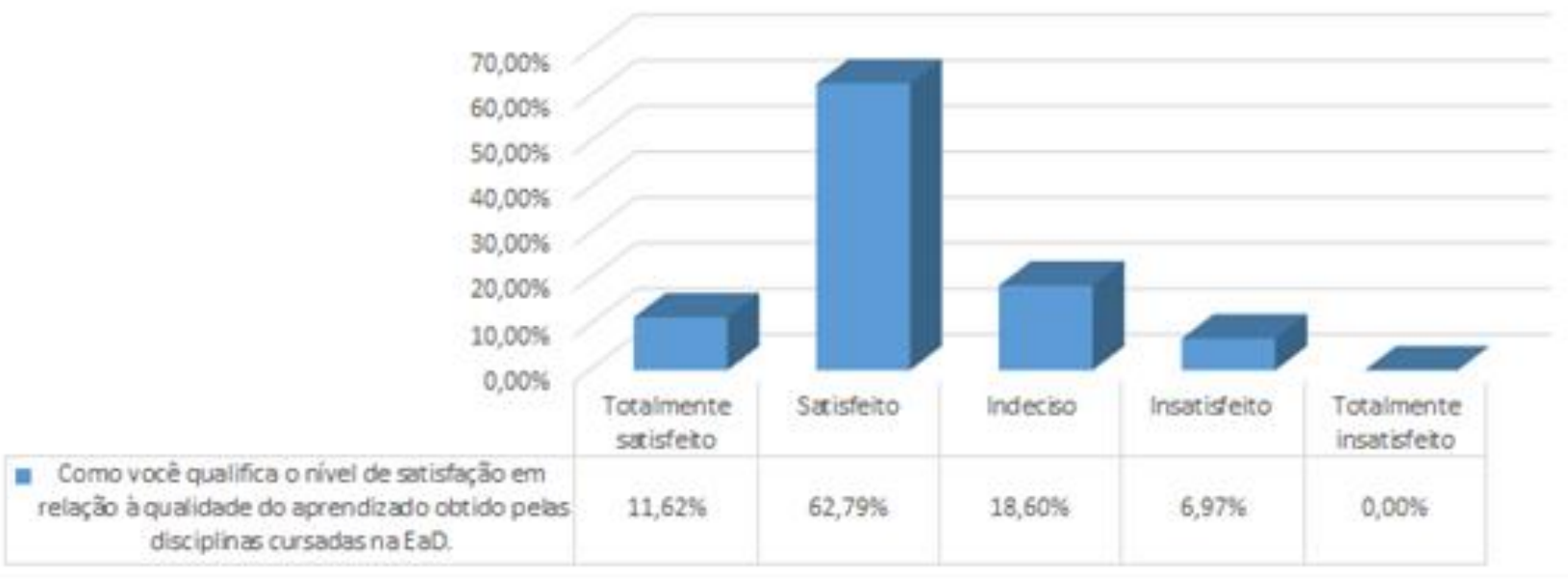

\section{Gráfico 3: Apreensibilidade}

Apesar de todas as divergências em relação às ferramentas, esse não parece ser um problema tão prejudicial ao aprendizado, uma vez, como é mostrado no gráfico acima, que $74,44 \%$ dos entrevistados se mostram satisfeitos quanto à qualidade de ensino oferecida pelo IFRN nessa modalidade de ensino a distância, mas especificamente pela qualidade do ensino proporcionado por meio do ambiente virtual de aprendizagem. De outro modo, $18,60 \%$ estão indecisos quanto a essa questão, enquanto 6,97\% estão insatisfeitos.

Para 41,86\% dos entrevistados, o Moodle contribuiu também no aumento da produtividade dos mesmos, nos quais $90,56 \%$ dentre os que afirmam que "sim" e "frequentemente", também estão satisfeitos com a qualidade de aprendizado obtido. Uma porcentagem bem inferior $(3,48 \%)$ de alunos afirma que não houve contribuição por parte do ambiente virtual de aprendizagem em relação a sua produtividade quanto ao ensino e aprendizagem.

Em relação à facilidade de utilização do Moodle (Gráfico n. 4), os dados se mostraram satisfatórios, pois $75,57 \%$ dos entrevistados disseram estar satisfeitos ou totalmente satisfeitos, com uma porcentagem de $15,11 \%$ de indecisos e $9,30 \%$ de insatisfeitos. 


\section{Facilidade em operar e controlar o Moodle}

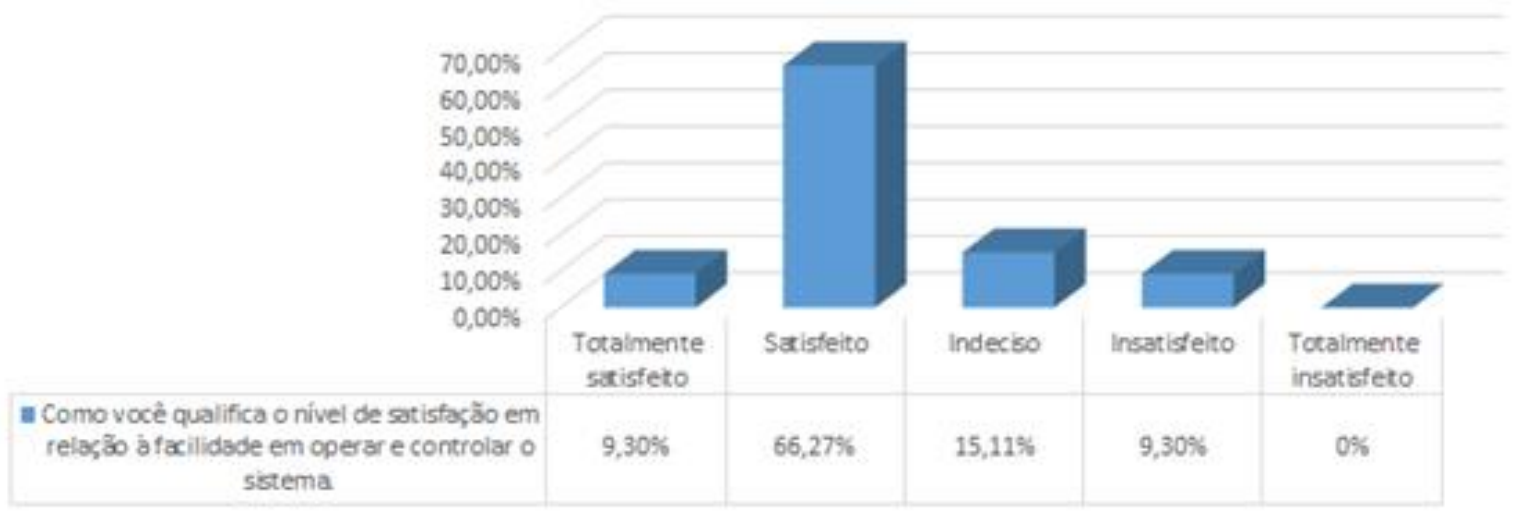

Gráfico 4: Inteligibilidade

A facilidade em operar e controlar o Moodle também depende da facilidade em aprender a utilizá-lo. Desse modo, $68,22 \%$ dos entrevistados estão satisfeitos ou totalmente satisfeitos, $22,35 \%$ indecisos, $8,23 \%$ insatisfeitos e 1,17\% totalmente insatisfeitos. Essa informação é coerente com as análises descritas mais acima a respeito da disciplina disponibilizada no início do curso.

Em linhas gerais, a respeito da satisfação dos alunos em relação ao ambiente virtual de aprendizagem como um todo, os resultados se mostraram positivos quando o tema é a utilização do Moodle, haja vista que $77,64 \%$ dos entrevistados se mostraram totalmente satisfeitos ou satisfeitos, enquanto $16,47 \%$ se dizem indecisos e apenas $5,88 \%$ insatisfeitos. De toda forma, esses dados positivos não excluem uma necessidade de uma contínua atualização e busca por melhorias por parte da instituição de ensino que provê o referido sistema.

\section{Satisfação geral com o ambiente}

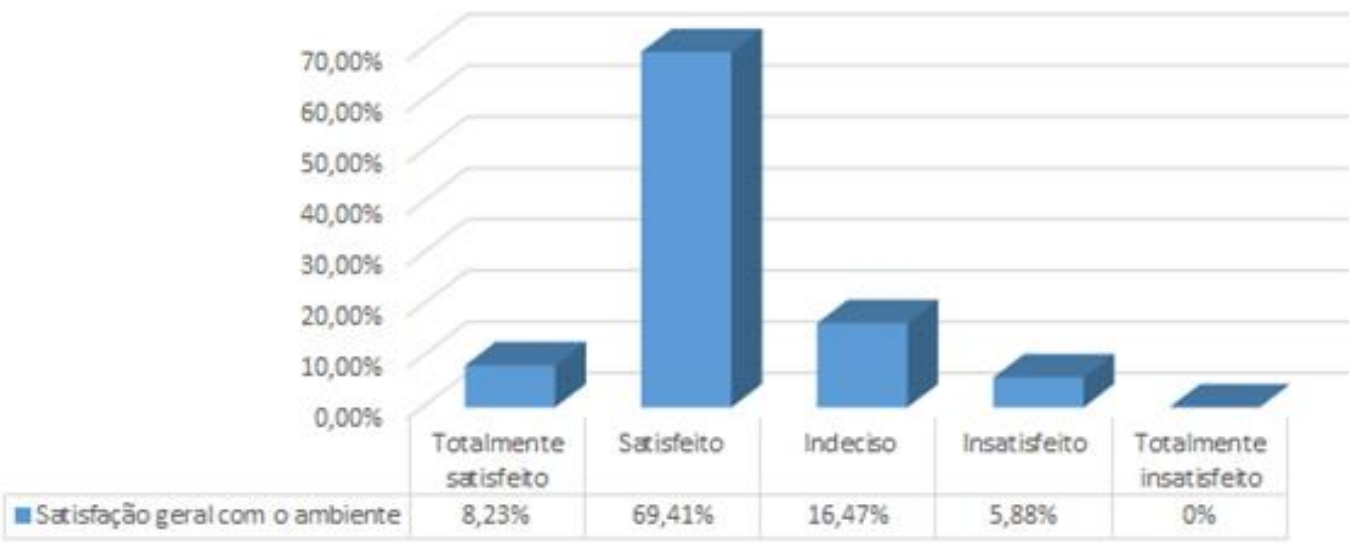

Gráfico 5: Satisfação dos usuários com o Moodle

\subsection{Outros dados relevantes - questões subjetivas}

As questões discursivas apresentaram uma percepção dos alunos um pouco mais ampla a respeito do Moodle, que dificilmente poderia ser alcançada apenas através das respostas oriundas das questões objetivas. Os comentários positivos ajudaram na compreensão do resultado final, cujos dados apontam que a maioria se mostrou satisfeita com o ambiente virtual de aprendizagem atualmente utilizado, e os comentários negativos ajudaram a compreender quais os maiores desafios e problemas percebidos pelos alunos, o que pode gerar reflexões interessantes em busca 
de melhorias para tais obstáculos. Assim, as sugestões apresentadas pelos alunos se mostraram coerentes e bem articuladas com as suas reais necessidades.

Nem todos os entrevistados se dispuseram responder as perguntas discursivas, o que rendeu uma média de 52 respostas em cada uma das duas questões.

Na primeira pergunta que trata dos pontos positivos do moodle, destaca-se a simplicidade e facilidade no uso, bem como a oferta de ferramentas ou recursos que fazem muita diferença para os alunos, gerando resultados bem satisfatórios. Dessa maneira, compreende-se o porquê dessa satisfação, pois não é requerido muitos conhecimentos tecnológicos para utilizar a plataforma, e a mesma oferece a maioria dos recursos essenciais ao aluno da educação a distância, ou seja, já é "bom o suficiente" como muitos disseram.

No que tange a segunda questão, percebeu-se que um dos aspectos que deve ser melhorado é o design do moodle. Segundo os alunos, ele é "bom o suficiente", mas não os atrai, isto é, não é um ambiente atrativo ao ponto de ser bastante agradável. Nesse quesito, alguns reclamaram das cores, fontes e da desorganização, todavia, o ponto negativo principal foi design. Assim, não seria necessário mudar cores e fontes se o design fosse mais atrativo.

Outro ponto importante que foi avaliado de forma insatisfatória por parte dos respondentes é a proteção contra erros, pois os erros geralmente ocorrem em atividades comuns ao sistema, como a resolução de questionários e/ou atividades.

As sugestões elencadas vão desde a correção desses erros anteriormente descritos, a disposição de elementos no site, até o melhor uso das ferramentas, sem esquecer das melhorias relacionadas ao design. Para melhor visualização dessas sugestões de melhoria, o Quadro 1 traz de forma resumida essas observações:

\section{CONCLUSÃO}

Os resultados da pesquisa permitiram a observar que o Moodle analisado não está totalmente em conformidade com as normas de usabilidade (NBR 9126), pois mesmo apresentando resultados positivos nos requisitos de inteligibilidade, apreensibilidade e operacionalidade, o sistema falha nos quesitos de atratividade e gestão de erros.

Tais deficiências se mostraram prejudiciais levando em consideração que o nível de satisfação quanto à qualidade de ensino é de aproximadamente $73 \%$. Apesar de ser um resultado acima dos $50 \%$, ele não se mostra satisfatório, uma vez que $84,80 \%$ dos entrevistados cursaram mais de 5 disciplinas em EaD.

Conforme as informações dos alunos, o que realmente prejudica a qualidade do ensino nesse tipo de modalidade é a falta de atratividade do sistema e a baixa de gestão de erros. Portanto, entende-se ser necessário que mudanças ou melhorias sejam realizadas no sistema, para que este possa atender adequadamente às necessidades dos alunos de maneira satisfatória.

Por último, destaca-se que a pesquisa foi realizada somente com os alunos da educação a distância do IFRN - Campus Currais Novos, o que torna as análises e resultados limitados e específicos, não podendo ser generalizados para outros sistemas de aprendizagem virtuais utilizados em outras instituições. 


\section{REFERÊNCIAS BIBLIOGRÁFICAS}

1. Acerca de Moodle. Disponível em: <https://docs.moodle.org/all/es/Acerca_de_Moodle> Acesso em 26 de agosto de 2014.

2. ALMEIDA, Cleibson. Debatendo o Papel do Tutor na Educação a Distância. In: Ambientes Virtuais de Aprendizagem. I Encontro Nacional de Educação a Distancia. Ribeirão Preto, 2006.

3. ALVES, Paulo; PIRES, José A.. A usabilidade em software educativo: princípios e técnicas. 2002. 5 f. Curso de Tecnologia e Gestão, Escola Superior de Tecnologia e de Gestão Instituto Politécnico de Bragança, Bragança, 2002.

4. BARROS, Aidil Jesus da Silveira; LEHFELD, Neide Aparecida de Souza. Fundamentos de metodologia científica. 3. ed. Petrópolis: Pearson - Makron Books, 2007. 176 p.

5. CISCO SYSTEMS (EUA). Internet Learning Solutions Group E-Learning Glossary. 2001. Disponível em: <http://www.puw.pl/sites/default/files/content_files/zasob_do_pobrania/358/elearningglossary-cisco.pdf>. Acesso em: 20 ago. 2014.

6. FRANCIS, Carlos. ENTREVISTA ABED. [mensagem pessoal] Mensagem recebida por: <silviazcoelho@terra.com.br>.em: 19 maio 2002.

7. FREITAS, Angilberto Sabino; Bertrand, Hélène (Orientadora), Silva, José Roberto (coorientador). A implementação do e-learning nas escolas de gestão: um modelo integrado para o processo de alinhamento ambiental. Rio de Janeiro, 2009. 330p. Tese de Doutorado Departamento de Administração, Pontifícia Universidade Católica do Rio de Janeiro

8. GOMES, Maria João (2005). Desafios do E-Learning: Do Conceito às Práticas. In Bento D. Silva \& Leandro S. Almeida (coords.), Actas do VIII Congresso GalaicoPortuguês de PsicoPedagogia, Braga: CIEd / IEP / UM, 66-76. [ISBN: 972-8746-36-9, CD-Rom].

9. IBOPE, 2010. Internet Release Fevereiro 2010: 67,5 milhões de pessoas têm acesso à internet no Brasil. 14/05/2010. Disponível em: <http://www.almanaqueibope.com.br/asp/busca_doclnfo.asp> Acesso em 24 de agosto de 2014.

10. LEVY, S. Six Factors to Consider when Planning Online Distance Learning Programs in Higher Education, Online Journal of Distance Learning Administration, n.1 vol.6, 2003.

11. LIMA, Jorge Reis; CAPITÃO, Zélia. E-learning e e-conteúdos: Aplicações das teorias tradicionais e modernas de ensino e aprendizagem à organização e estruturação de e-cursos. Famalicão: Centro Atlântico, 2003. 288 p.

12. MCKIMM, J;JOLLIE, C; CANTILLON, P. ABC of learning and teaching - Web based learning. BMJ 2003.

13. MEDEIROS, Marco Aurélio; CYBIS, Walter de Abreu. Método de avaliação de usabilidade de software a partir da satisfação de usuários e da aplicação de quesitos da norma ISO 9241. 2000. 9 f. Curso de Engenharia de Produção, Laboratório de Utilizabilidade de Informática, Universidade Federal de Santa Catarina, Florianópolis, 2000.

14. MILLIGAN, C. Delivering Staff and Professional Development Using Virtual Learning Environments. In: The Role of Virtual Learning Environments in the Online Delivery of Staff Development. Institute for Computer Based Learning, Heriot-Watt University, Riccarton, 
Edinburgh EH14-4AS, 1999.

15. MOODLE. Home. Disponível em: <https://moodle.org/> Acesso em 24 de agosto de 2014.

16. NIELSEN, Jakob; LANDAUER, Thomas K. A mathematical model of the finding of usability problems. In: Proceedings of the INTERACT '93 and $\mathrm{CHI}$ '93 Conference on Human Factors in Computing Systems (CHI '93). New York, NY, USA: ACM, 1993. P. 206-213.

17. NORMA ISO 9126. Disponível em: < http://usabilideiros.com.br/index.php/qualidade-desoftware/item/5-norma-iso-9126> Acesso em 29 de janeiro de 2015.

18. PEREIRA, Alice Cybis; SCHMITT, Valdenise; DIAS, Maria Regina Álvares C. Ava: Ambientes Virtuais de Aprendizagem: Em Diferentes Contextos. Rio de Janeiro: Ciência Moderna, 2007. $232 \mathrm{p}$.

19. ROSENBERG, Marc J.. E-Learning: Implementando com sucesso aprendizado on-line na sua empresa. São Paulo: Makron Books, 2002.

20. SENACH, Bernard. L'Évaluation ergonomique des interfaces homme-machine. Une revue de la littérature. In: SPERANDIO, Jean-Claude. L'ergonomie dans la conception des projets informatiques. Toulouse-France: Octares Éditions, 1993.

21. SILVA, Alandey Severo Leite da et al. A Usabilidade como Capacidade Inovativa em Ead: Um Estudo em uma Instituição Particular de Ensino Superior. In: ENANPAD, 38., 2014, Rio de Janeiro. Rio de Janeiro: Anpad, 2014. p. 1 - 15.

22. SOELTL. E-Learning Brasil. 2010. Disponível em: <www.elearningbrasil.com.br>. Acesso em: 24 ago. 2014.

23. SOUZA, A. C. Proposta de um processo de avaliação da usabilidade de interfaces gráficas de sistemas interativos computacionais, através da integração das técnicas prospectiva, analítica e empírica. 2004. 263 f. Tese (Doutorado em Engenharia da Produção), Programa de PósGraduação em Engenharia de Produção, Universidade Federal de Santa Catarina - UFSC. Florianópolis. 